\title{
Updating the Role of Rural Supervision: Perspectives from Alaska
}

\author{
Ute I. Kaden ${ }^{1}$, Philip P. Patterson ${ }^{1} \&$ Joanne Healy ${ }^{1}$ \\ ${ }^{1}$ School of Education; University of Alaska Fairbanks, Fairbanks, Alaska, USA \\ Correspondence: Ute Kaden, School of Education; University of Alaska Fairbanks, Fairbanks, Alaska 99775-6480, \\ USA.
}

Received: March 3, 2014

doi:10.11114/jets.v2i3.364
Accepted: March 20, $2013 \quad$ Online Published: May 5, 2014

URL: http://dx.doi.org/10.11114/jets.v2i3.364

\begin{abstract}
Despite the documented importance of professional experiences in teacher preparation, numerous questions persist as to how university supervisors can effectively contribute to rural preservice teachers' development and to establish lasting collaborations between involved stakeholders (e.g., collaborating teacher, principal, community). This paper provides insight into the challenges and potential for a comprehensive and updated approach to in-person supervision in a rural sociocultural context. Transcriptions of field notes, observation protocols, and conversations from forty supervision travels to remote Alaska villages are examined and interpreted. Results support a fresh, rural-contextual approach to in-person supervision that has the potential to help preservice teachers not only master effective teaching strategies but also support teacher recruitment, retention, and collaboration.
\end{abstract}

Keywords: rural education, teacher education, supervision, professional experiences, student teaching

\section{Introduction}

The significance of high-quality professional experiences (also known as field placements, student teaching, practicums, or clinical practices) in preservice teacher education is well documented (Anderson \& Stillman, 2012;

Darling-Hammond, 2012; Ingersoll \& Strong, 2011). University faculty supervision of professional experiences is an integral part of quality teacher education programs (Zeichner, 2012). Supervision of professional experiences occurs in the organizational, sociocultural, and political context of schools' locations and should focus on context-specific principles of practice that promote justice and equity (Eppley, 2009; Reed, 2010; White \& Reid, 2008). However, research on rural professional experiences and teacher preparation for teaching in small rural schools that serve students with diverse and Indigenous heritage is limited.

In the United States, rural school districts serve more than $24 \%$ of the total student population (National Center of Education Statistics, 2010). Teachers in rural areas are held as equally accountable to fulfill federal and state education mandates as teachers in urban and suburban communities. The existing literature provides evidence that teachers in rural areas face conditions, which are both difficult and unique (Barnhardt, 2005; Corbett, 2009; Howley \& Howley, 2010; Kline, White, \& Lock, 2013). Such conditions require relevant preservice teacher preparation practices including supervised professional experiences in rural school settings, training in place-relevant pedagogy as well as support and information to develop cultural competencies.

In our paper we provide insight into in-person rural supervision and advance the need for effective clinical supervision as a vital investment for training, supporting, and retaining effective rural teachers. We argue for an expanded and updated model of in-person rural supervision, and demonstrate how rural supervisors can be more than instructional mentors to preservice teachers. We contend that a personalized and collaborative approach to rural supervision will advance local trust, teacher effectiveness, recruitment, and teacher retention.

\subsection{Research Questions}

The research questions for this study are:

(a) What are unique factors that influence practices of rural teaching and supervision?

(b) How could the in-person supervision model be updated and restructured to support education in rural schools?

In this paper, remote and isolated rural areas are defined as those located in sparsely populated communities in the United States, which are considerable distances away from other communities, especially urban centers (Howley \& Howley, 2010; Slack, Bourne, \& Gertler, 2003). Rural supervision as discussed in our paper occurs in regions with 
different local languages and heritages inclusive of Indigenous cultures. In such communities, Indigenous people have particularly strong connections to cultural, environmental, and spiritual practices (Corbett, 2009). For purposes of our discussion, direct clinical supervision is described as a series of in-person, supervised field experiences in Pre K-12 classrooms, which occur as a sequenced integral part of a teacher preparation program prior to candidates becoming certificated teachers. Additionally, university supervisors are defined as those who have been assigned by a university or college-based teacher preparation program to provide supervision and evaluation of professional experiences (Higher Education Opportunity Act, 2008).

\section{Contextual Framework}

\subsection{The Purposes and Outcomes of Supervision}

Expert supervision of preservice teachers in a highly stimulating, well-organized environment shortens the time it takes to develop effective teachers who can influence student achievement (Boyd, Grossman, Lankford, Loeb, \& Wyckoff, 2009). Researchers and practitioners agree that effective supervision has positive effects on both teachers and students, particularly if performed in the context of schools' communities (Barley, 2009). These positive outcomes are also affected by the quality and duration of supervision, the overall quality of the work environment, and the shared responsibilities and collaborations between school administrators, supervising teachers, and university faculty (Cochran-Smith et al., 2012; Cuenca et al., 2011; DeAngelis, Wall, \& Che, 2013). Specifically, quality supervision has been found to improve:

- Teachers' ability to reflect on instruction and expands instructional flexibility

- $\quad$ Context and place planned instruction that is achievement oriented, community based and grounded in good interpersonal communication

- $\quad$ Classroom management practices

- $\quad$ Student achievement and attitudes toward learning

- $\quad$ Collegiality, openness, and communication among teachers and between teachers, supervisors, and principals

- $\quad$ Enthusiasm about teaching and commitment to the profession

- $\quad$ Retention of teachers in the profession, while also reducing teacher anxiety and burnout.

- $\quad$ Teachers' sense of autonomy, personal efficacy, and self - growth (Butler \& Cuenca, 2012; Goldhammer, 1969; Krajewski \& Jones, 1997; Southgate, Reynolds, \& Howley, 2013).

Traditional supervision protocols tend to be focused on measuring standards of professional performance rather than on the stages of development a teacher experiences on the way to becoming an effective educator (Goldhammer, 1969; Hensley, 2003). Those standards for educators define what a teacher should know and should be able to do. Examples of organizations that develop such standards are the National Board of Professional Teaching Standards (NBPTS), the Council of Exceptional Children (CEC), the Association for Teacher Educators (ATE), and the National Science Teachers Association (NSTA).

Preservice teachers, however, are often intimidated and overwhelmed by the multitude of standards, which seem to depict a perfect educator: a type of ideal Ueber-teacher. Preservice teachers see little room for developmental stages or accepted struggles on their way to developing into master teachers (Range, Young, \& Hvidston, 2012). Those standards are well-intended and arguably needed as guidance for teacher education but can lack relevance for developing teachers and may discount diversity of the cultural and socio-economic contexts where teaching takes place.

One could claim that standards are broad-spectrum and universal, but we maintain that standards alone do not produce culturally competent teachers who have the capacity to effectively work in remote Indigenous communities. It could be argued that "standardized" teachers are only good for a homogeneous and normed society, which does not exist in reality. Allan Luke (2012) writes: "Educators now face a push for standardization that exceeds the imperatives for interoperability, where rationalizations of fairness are used to justify sameness, to flatten out diversity and ignore difference (p. 375)".

\subsection{Supervision and Technology}

Recently, better access to technology and distance communication infrastructure combined with pressing budget shortages and the extremely high costs of rural supervision travel have led to the development of distance based supervision options that have the potential to supplement or replace in-person clinical supervision (Kopcha \& Alger, 2011). The literature has identified a variety of technologies (e.g., video conferencing, online management systems, telephone conferencing, etc.) that can facilitate observations of live classroom events as well as provide for remote coaching and evaluation of preservice teachers (Jung, Galyorn-Keramidas, Collins, \& Ludlow, 2006). Although promising, technologies may prove problematic in some remote and isolated rural areas depending upon Internet 
availability, bandwidth, and satellite access. Recent research supports the importance and value of personal relationships, communication, and in-person supervision for effective teacher education programs (Ingersoll \& Strong, 2011; Santoli \& Martin, 2012; Zeichner, 2012). There is strong evidence that models that combine technology supported distance supervision with in-person visits are promising alternatives in teacher education programs (Plonczak, 2010).

\subsection{A Rural Contextual View}

Supervisors are in unique positions to bridge the perceived uneasy divide between the theoretical content of teacher preparation programs and the practical knowledge of teaching in an actual school context (Cuenca, Schmeichel, Butler, Dinkelman, \& Nichols, 2011). Rural local interests and national requirements for accountability and education reform do not always match. Often, these interests and mandates result in tensions that politicize the classroom. Recent reports continue to document distrust and conflict between rural communities and the federal education establishment (Eppley, 2009; Fry \& Anderson, 2011; Reid et al., 2010; Strange, 2011). Fears of losing cultural heritage and identity including language and Ways of Knowing (Barnhardt, 2005; Kisker et al., 2012) seem to be woven into the educational tapestry of remote rural regions that serve Indigenous populations. Persistent high dropout rates, lower educational achievement, and the lack of passion for formal schooling amongst some Indigenous students are rooted in inadequate learning environments, questionable teaching methods and alien institutional curricula (Eppley, 2009; Kisker et al., 2012). Current United States education policies, the new Common Core State Standards Initiative and mandated teacher evaluation systems have a dangerous potential to increase those educational divides, uncertainties, outcomes, and fears. As a result, needed community participation in rural education is slow, recruiting residents into the teaching field difficult, and training, supervising, and retaining teachers in rural areas challenging (Kline et al., 2013; Ryan, Jones, \& Walta, 2012). Present statistics reflect the situation by documenting an increasing achievement gap and essentially flat scores on standardized tests for Native American students (National Center of Education Statistics, 2011).

Rural schools face difficulties hiring and retaining effective teachers as well as attracting local people into the teaching profession (Eppley, 2009; Stelmach, 2011). Challenges for many rural school districts include a monotonous annual cycle of recruitment, training, and attrition. Students in rural areas must often contend with an ever-rotating series of teachers who are learning on the job (Henry, Bastian, \& Fortner, 2011; Ronfeldt, Loeb, \& Wyckoff, 2012). Children in rural schools, however, deserve high quality education with teachers who understand the importance of place, value students' lifeworlds, and are capable of building appropriate teaching and learning opportunities (White \& Reid, 2008). It is important to prepare a teaching workforce that is able to meet the unique challenges of rural schools. Effective professional experiences and supervision of preservice teachers in rural areas is fundamental to the development of a rural workforce. For rural geographic regions in Alaska, Australia, Canada, New Zealand and elsewhere with significant rural student populations and Indigenous heritages, context-bound training is critical.

\subsection{The Alaska Context}

Recent statistics show that more than $75 \%$ of new yearly hires by rural Alaska school districts are teachers or teachers in training from the "Lower 48" (not from Alaska). High yearly turnover rates of $23 \%$ to up to $100 \%$ in some rural schools are common (Hill \& Hirshberg, 2013). More than $80 \%$ of supervisees who are hired by rural school districts on the basis of provisional certification or waivers have no previous teaching or living experiences in rural schools. Their hiring and moving to rural Alaska coincides with entering the university-based alternative teacher certification and supervision program. Often newly hired teachers are the only experts in their subject areas and may carry responsibilities for all courses and in all grade levels. In addition, they often teach outside their area of certification and direct many hours of extracurricular activities (Reid et al., 2010; Strange, 2011). This situation illustrates the unique working conditions and the high need for qualified and effective teachers in rural Alaska.

Preservice teachers participating in professional experiences are often expected to patiently, quickly, and successfully assimilate into unfamiliar school and community cultures. Those expectations are more challenging in small rural schools, where the inevitable scrutiny of a new face is more likely to extend beyond the school walls (McCracken \& Miller, 1988). For example, more than $25 \%$ of Alaska's rural schools have less than 50 students with only two or three full time teachers employed. In such schools, a principal-teacher often fulfills the role of principal. If a full time principal position exists in a rural school, the principal may be responsible for two or more schools within the district. As a result, on-site mentoring of preservice teachers can be limited. Additionally, a collaborating teacher who supervises a preservice teacher may teach in a different subject area or may not be available at all. Thus, it is critically important that preservice teachers need to learn to self-reflect on their effectiveness in the classroom, a factor associated with resiliency and persistence (Elliott, Isaacs, \& Chugani, 2010).

\subsection{The Teacher Preparation Program}

The secondary post-baccalaureate licensure program portrayed in this study is a university based teacher preparation program that can be completed in one calendar year. It is designed to prepare candidates who hold bachelors degrees 
from accredited universities for teaching in grades 7-12. The program is field-based and prepares candidates to teach in multi-cultural, diverse settings with a special focus on teaching in remote and rural Alaska locations. Preservice teachers are placed at the beginning of the program in schools that may be located in communities ranging from very small rural villages accessible only by air or boat to urban areas having populations of several hundred thousand residents. Less than $20 \%$ of the preservice teachers supervised are traditional candidates: those who complete a four or five year teacher education program. Many current rural supervision assignments involve candidates (ages 19 to over 60) with baccalaureate degrees who are hired by rural districts as full time teachers while working on teacher licensure, special education certification, or master's degree in education with a teacher licensure option. This group of educators is referred to as Teachers While Training (TWT). These candidates are also concurrently enrolled in a one or two year teacher certification program. This type of teacher certification method is often referred to as an alternative program. Such programs tend to attract a more heterogeneous group of prospective teachers who possess a range of academic, professional, and life experiences but whose proficiencies rarely include teaching and living experiences in rural and remote areas.

\section{Methods}

3.1 Design

The present study was designed to identify factors that influence current practices in rural supervision and teaching, to discuss challenges, and to show how in-person supervision could be updated to comprehensively support education in rural schools. This study used a qualitative research design to better understand rural supervision of teacher candidates (Creswell, 2007). Findings from this paper are based on 40 rural in-person supervision visits of 20 secondary teacher candidates from 2008 to 2012. The sample is a convenient sample based on the researchers' rural field supervision assignments during this time period. The primary data sources for this paper included (a) supervision/observation reports and field notes; (b) supervisees reflections on teaching, planning, and work conditions; (c) and transcripts from conversations with supervisees and local collaborators (administrators, principals, mentor teachers, and community members). Phenomenological perspectives, narrative inquiry, and ethnographic methods supported our interpretation and understanding of the changes in assessment practices of the preservice teachers (Moustakas, 1994). Vallack (2010) identifies this type of research as subtextual phenomenology. Underlying assumptions in this phenomenological approach are that knowledge is constructed through social interactions within a community context and that individuals understand their world through experiences and interpretation. Epistemologically, phenomenological approaches are based in a paradigm of personal knowledge, experience and subjectivity, and emphasize the importance of personal perspective and interpretation (Bogdan \& Biklen, 2007). We engaged in reflective writing and conversations to systematically explore our own thinking about the emerging themes and information (Kleinsasser, 2000; Miles \& Huberman, 1994).

\subsection{Sample and Data Collection}

Data was collected from 40 rural in-person supervision visits. Twenty secondary teacher candidates, 12 females and 8 males, located in eighteen rural schools communities were visited twice during the supervision period. Nine of the participants were Teacher While Training (TWT) candidates and 11 were enrolled in a one-year university based secondary post baccalaureate-teaching program. The average age of the supervisees was $27(\mathrm{SD}=8.9)$ and ranged from 19 to 55. Subject areas of the candidates included mathematics, science, English Language Arts, social studies, and special education. All participants were housed in the rural communities during the supervision period (e.g., spring/fall semester). The average rural school sizes where supervision took place ranged from 11 to 400 students with more than 90\% indigenous students enrolled. All communities were located in rural Alaska and off the road system, accessible by air or boat only. During supervision visits collaborators (administrators, principals, mentor teachers, and community members) participated in discussions and evaluations of the supervisees progress toward teaching in a rural context.

\subsection{Data Analysis}

Data sources were evaluated using the constant comparative method (Glaser \& Strauss, 1967) in which inductive coding and sorting allowed themes and factors unique to rural supervision to emerge. Categories were created to develop theory and explanations to identify unique factors that influence practices of teaching and rural supervision (Walker \& Myrick, 2006). The categories include unique factors of rural supervision, frequent supervisor activities and essential partnerships/communication. Frequencies of identified factors unique to rural supervision and teaching were recorded and analyzed using descriptive statistics. In addition, we carefully reviewed our supervision protocols and field notes to develop a coding system for common supervisor activities. Six themes emerged and are reported in Table 2 as frequent supervisor activities during rural school visits in percent of occurrence. As university supervisors we developed understanding by having sustained, intensive engagements with the participants during the study and recognize that personal biases may exist. However, we reexamined our findings and interpretations carefully, and feel that our 
experiences strengthen the accounts of the paper.

\section{Findings}

Analysis of our data revealed that university supervisor responsibilities for teaching candidates in rural schools are complex, necessary, and need to be updated. After coding the data sources the following themes emerged: (1) unique factors that influence practices of rural supervision and teaching, (2) frequent supervisor activities during rural school visits, and (3) essential partnerships, collaboration, and frequently asked question for the supervisor.

\subsection{Unique Factors}

Our findings indicate that professional experiences in rural schools are diverse. Frequencies of identified factors unique to rural supervision and teaching compiled from coding documents from 40 supervision visits and supervisee reflections are summarized in Table 1.

Supervision travel costs, time commitment, and logistics make rural supervision an intense experience for the supervisor. However, the personal experiences and conversations during the stay in a rural community are essential for understanding individual challenges, and the work context of rural preservice teachers and to inform the university education program. Small school size and instructional skills on how to modify teaching strategies and curriculum to the rural context are challenging factors for supervisees. Data indicate that rural schools that are guided by experienced and supportive leadership have many unique advantages for professional experiences. Attributes of such rural schools may include strong teacher student relationships, flexible scheduling, individualized teaching, motivating place relevant curricula, an atmosphere of caring and respect, the beauty of the natural environment, and interesting cultures and languages. However, our research results also show that rural schools may not have the senior personnel to provide guidance and mentoring for preservice teachers. Preservice teachers reflected that collegiality and networking opportunities are critical to their success. However, these opportunities are not available at all rural schools. Additionally, unfamiliarity with rural living conditions and Indigenous cultures, the Arctic environment, and community relations added to emotional stress and feelings of isolation during professional experiences. We also discovered during our visits esoteric local factors that influenced the success of teacher candidates. Such factors included overall living conditions, school supplies, curriculum or the lack thereof, involvement in after-school programs, new value added evaluation practices, administrative leadership, and variable community involvement.

The rural supervisor needs to be prepared to address those factors individually, preferably at the location where the professional experience takes place. During our visits the majority of the teachers, administrators, and preservice teachers indicated that in-person visits by the university supervisor were essential to understand their working conditions, accomplishments, and challenges in the context of their local schools and rural communities. Our data support the notion that in order to highlight success and to mitigate possible problems, in-person supervision is needed for rural professional experiences.

Table 1. Factors identified frequently as unique to rural supervision and teaching during 40 rural visits $(\mathrm{N}=40)$

\begin{tabular}{|c|c|c|}
\hline Factors & Descriptions & Frequencies \\
\hline $\begin{array}{l}\text { Supervision travel and remote } \\
\text { locations }\end{array}$ & $\begin{array}{ll}\text { - } & \text { Long distances and extensive time commitment (1 to } 3 \text { days) } \\
\text { - } & \text { High costs involved (expensive) } \\
\text { - } & \text { Multiple modes (e.g., air, boat, ATV) of transportation } \\
\text { (adventures) } \\
\text { - } \\
\text { - } \\
\text { Traditional lodging often not available (hard school floors) } \\
\text { Supervisor travel fatigue (intense) }\end{array}$ & $\begin{array}{l}40 \\
40 \\
38\end{array}$ \\
\hline $\begin{array}{l}\text { Small schools } \\
\& \text { Learning to teach in a rural } \\
\text { cultural context }\end{array}$ & $\begin{array}{l}\text { - Teaching assignment mandates place relevant and culturally } \\
\text { - } \quad \text { Atrong teacher- student relationships (rewarding) } \\
\text { - } \quad \text { (excellent and unique) } \\
\text { - } \quad \text { "Fime commitment for after school activities (long hours) } \\
\text { - Teaching assignments include multi age classrooms, } \\
\text { - } \quad \text { Impltiple subject areas (challanging and rewarding) } \\
\text { - Opportunities for professional exchange (limited) } \\
\text { - Senior mentor teacher in subject area often not available } \\
\text { (difficult) }\end{array}$ & $\begin{array}{l}40 \\
39 \\
38 \\
38 \\
37 \\
34 \\
30 \\
22 \\
20\end{array}$ \\
\hline
\end{tabular}


- $\quad$ Principal may be housed in a different school hundreds of 14 miles away (challenging)

Living in small rural communities

Community relations \& preservice teachers
- Teacher housing (the good, the bad, and the none existing) 32

- Arctic natural conditions (beautiful and dangerous) 32

- Access to specialized health care (long distances off) 28

- Access to childcare (problematic) 27

- Internet availability and reliability (improving) 20

- Interesting culture, languages, and rural context (rewarding) 40

- Adjustment to rural life (multifaceted experience) 35

- Community integration (very rewarding but also difficult) 34

- Understanding and involvement in indigenous cultures 33

(interesting, rewarding, and challenging)

- $\quad$ Parental support (strong, indifferent, or opposed) 33

\subsection{Frequent Supervisor Activities}

Coding supervision reports and field notes of the supervisor during the visits and recording frequencies and percent of occurrences during the visits revealed that the most common supervisor activities during rural school visits include: providing individualized instructional, professional, and emotional support for supervisees based on traditional supervisor responsibilities (100\% of the visits). Additional activities encompassed meeting with administrators and educational stakeholders (93\% of the visits), touring the school and community ( $88 \%$ of the visits), providing teaching resources and supporting curriculum development for rural teachers (58\% of the visits), presenting information on pathways towards entering and staying in the teaching profession (35\% of the visits), and conducting professional development (25\% of the visits). Those results support the comprehensive workload of the rural supervisor.

Table 2. Frequent supervisor activities during rural school visits $(\mathrm{N}=40)$

\begin{tabular}{lc}
\hline Supervisor activities & Frequency \\
\hline Providing individualized instructional, professional, and emotional support to supervisees. & $40(100 \%)$ \\
Meeting with administrators and educational stakeholders. & $37(93 \%)$ \\
Touring the school and community. & $35(88 \%)$ \\
Providing teaching resources, and supporting curriculum development for rural teachers. & $18(45 \%)$ \\
Presenting information on pathways towards entering the teaching profession. & $14(35 \%)$ \\
Conducting professional development for staff. & $10(25 \%)$ \\
\hline
\end{tabular}

\subsection{Partnerships and Frequent Questions for the Supervisor}

Collected data identify collaboration, planning, and communication as essential elements for implementing successful professional experiences. Administrators, principals, school staff, and community members are reported as actively involved collaborators of professional experiences in various capacities. It is essential that all partners know the expectations of the teacher education programs and that they are made aware of individual responsibilities (e.g., principal, mentors teacher, supervisor). In addition, rural supervisors frequently respond to questions from collaborators about the extent of preparedness of preservice teachers to: facilitate learning in multi-age classrooms; teach multiple subjects; place-based education; work with diverse and special needs students; integrate technology into the curriculum; and supervise distance education. Questions concerning workload and responsibilities of the preservice teacher (e.g., possible or needed hours of student teaching, substitute assignments, and after school commitments) needed frequent clarification or required collaborative decisions based on the local needs and individual abilities. Information about overall academic standing and the type and frequency of university course work were identified as important topics of conversations between the parties. Negotiating and identifying where candidates may need more support from the university and/or school, possible collaboration in professional development delivery, curriculum design, and support for recruitment of locals into the teaching profession are also frequently discussed.

\section{Discussion and Recommendations}

\subsection{A Fresh and Updated Perspective for Rural Supervision}

Based on the themes that emerged from our field notes, observations, and frequent interaction with candidates, in-person visits from university supervisors, who are sometimes seen as neutral to school politics, are very important 
from a human aspect. They are critical for providing support for completing university assignments and for clarifying responsibilities. The supervisor can often negotiate between parties and provide support when needed. Preservice teachers require understanding, support, a safe environment to grow, and a workload that is reasonable and reflective of their new practitioner status.

Supervision of professional experiences is mandated by state and national licensing agencies that accredit teacher education programs. Teaching, however, is a cultural and social practice and not a one-size-fits-all enterprise. Our study shows that rural supervision in Indigenous communities includes modeling place relevant education and culturally responsive teaching practices to make education meaningful to students. Focused planning of tasks before the visit, observations and activities during the visit, and feedback after the visit are essential.

Besides exceptional knowledge in classroom management, pedagogy, child development psychology, and sociocultural aspects of teaching, a rural supervisor needs to be a good listener, careful observer, respectful educator, and patient learner. It is of critical importance that the supervision process be fundamentally humane (Goldhammer, 1969). The in-person communication between the supervisor and the preservice teacher immediately after a classroom observation, the detailed evaluation of the lessons taught as well as a focus on understanding and support are elements that foster a professional relationship, which combats feelings of isolation. Isolation, loneliness and missing professional support are well-documented reasons why some preservice and new teachers leave rural areas (Kline et al., 2013; Ryan et al., 2012; Strange, 2011; Wenger, Dinsmore, \& Villagómez, 2012). Being resourceful, humorous and approachable, along with having a respect for local culture and an understanding for the challenges preservice teachers face, are essential traits of effective rural supervisors.

Assessing lesson planning and delivery strategies by observing lessons taught by preservice teachers is only part of the supervision duty. A preservice teacher in a rural setting has to teach and live in a way that is understood by the community. As a result, the supervisor has to support community integration, place relevant instructional competencies, and has to be prepared to give emotional support when needed.

To augment in-person supervision visits universities currently explore various forms of distance observation. It is seen by some as an effective solution to curb high costs associated with travel during supervision. Yet, problems that occur during professional experiences can be messy and context related. They are rarely detectable or solvable by telephone or video conferencing. Such unresolved issues can threaten the success and longevity of preservice teachers. Many problems can often be easily resolved during visits by engaging in reflective practices within the context of the preservice teacher's work environment. The intricacies of preparing rural educators and the spirit of culturally diverse populations are not easily transmitted through a digital cable. There is no doubt, however, that digital supervision can be part of the overall supervision plan during professional experiences and further research on this topic is needed.

\subsection{Communication, Negotiation, and Collaboration}

Our findings show that a partnership approach to planning and preparing for professional experiences in rural areas is required. A university supervisor has some advantages as a neutral observer and unbiased negotiator to facilitate contact, understanding, and communication between rural stakeholders and preservice teachers. A supervisor has to assess that the small school is a safe place for the teacher to grow. Poor communication, missing resources, a generally indifferent working environment, and overall loneliness can lead to job dissatisfaction and early burnout of preservice teachers (Munsch \& Boylan, 2008). Facilitating communication between all parties may strengthen personal relationships and collegially. Research supports that those factors are particularly important for the development, job satisfaction, and retention of rural teachers (Castagno \& Brayboy, 2008; Eppley, 2009).

Another area of needed collaboration concerns recruitment of future local teachers and university program support for noncertified school staff. Many of the rural schools have excellent local paraprofessionals or teacher aides that are interested in pursuing teacher licensure. In addition, future educator clubs in some schools organize high school students who are interested in teaching careers (e.g. Future Educators of Alaska). Those local residents know their communities well, speak the local language, and have strong ties to cultural practices, businesses, and community institutions. The rural university supervisor can help to recruit linguistically and culturally diverse local teacher candidates and promote teacher certification. The supervisor may also help to establish a university-school partnership that can support local teacher candidates, create rural practicum placements for preservice teachers, and provide professional development, which strengthens content knowledge and skills of local teachers. In summary, the rural university supervisor is an ombudsman: acting as a resource, evaluator, communication expert, neutral participant observer, counselor, professional development organizer, and college advisor and recruiter. Recommendations for the updated role of the university supervisor to support teacher retention, recruitment, and instruction can be found in Table 3. 
Table 3. Updated role of the university supervisor

\begin{tabular}{|c|c|}
\hline Focus of updated supervision & Recommendations \\
\hline Teacher Retention & $\begin{array}{l}\text { - Offer professional development workshops for teachers and } \\
\text { staff during the visit. } \\
\text { - Support community integration by helping to utilize } \\
\text { community resources, information on rural living and rural } \\
\text { economics. } \\
\text { - Share university resources. }\end{array}$ \\
\hline Teacher Recruitment & $\begin{array}{l}\text { - Inform K-12 students, teacher aids, school staff, counselors, } \\
\text { and organizations such as future educators clubs about } \\
\text { pathways toward teaching and a teaching degree. } \\
\text { - Share information about access to college advising and } \\
\text { faculty. }\end{array}$ \\
\hline Instructional support & $\begin{array}{l}\text { Provide support in computer literacy and educational } \\
\text { technology. } \\
\text { Provide information about distance course offerings, dual } \\
\text { enrollment classes. } \\
\text { - Share information for content expert faculty and resources } \\
\text { on place relevant education (e.g. climate change } \\
\text { researchers, special education experts, curriculum writers, } \\
\text { ELA specialists). }\end{array}$ \\
\hline
\end{tabular}

\section{Conclusion}

Our paper illustrates the unique factors of rural schooling and how the in-person supervision model can be updated to a rural-contextual approach that supports education in the local communities. For the supervisor this approach involves recognizing the unique factors associated with rural schools and communities, becoming a resource for preservice teachers and school staff, and participating in on-going communication with all stakeholders. Such an approach has the potential to help preservice teachers not only to master effective teaching strategies in the sociocultural context of rural communities but also to develop resiliency. The rural supervisor is the visible human link between the institution of higher education and the rural community. The need to attract, prepare, and retain teachers continuous to present unique challenges to teacher preparation, universities, and school districts that serve rural areas (Barley, 2009; Eppley, 2009; Faircloth, 2009; Fry \& Anderson, 2011). Therefore, support for instruction, local recruitment, and teacher retention need to be part of the extended responsibilities of a university supervisor. The supervisor should provide first hand information about pathways toward teaching careers and offer professional development workshops to local teaching staff. Growing local participation in teacher preparation may be the catalyst for sustainable and locally directed change in teacher training and the education of rural and Indigenous youth. Our research supports the idea that the development of preservice educators takes place in the socio-cultural context of the rural community and requires personal contacts between local stakeholders and university program faculty. Knowing the local context, history and culture, and actively interacting with stakeholders of the local school and community are part of successful rural supervision.

The comprehensive tasks of rural supervision require university administrative commitment, training, and actual time spent in rural communities. It cannot be ignored that rural in-person supervision is an expensive proposition. However, rewards including the development of effective teachers who can engage rural students in learning may make funding of comprehensive in-person supervision an exceptional investment in the future of resilient and healthy rural schools and communities.

\subsection{Limitations}

It is acknowledged that the observations and reports collected from supervision experiences in rural Alaska and may not be generalizable. Rural Alaska villages are very remote and often off the road system. A majority of the communities are comprised of more than 90\% Indigenous residents (Hill \& Hirshberg, 2013). Each rural location has its own dynamics, socioeconomic and cultural characteristics, and history of schooling. Thus, some of the findings may apply only to a specific local context. In addition, phenomenological research as applied in this study must be tentative in suggesting the extent in relation to the population from which the participants or cases were drawn (Stake, 1995). Researcher biases may be present despite careful comprehensive analysis of data transcriptions and interpretations 
(Creswell, 2007). However, the overall observations may have the potential to augment teacher supervision practices in similar settings with rural characteristics.

\subsection{Further Research}

Further research should identify ways toward community based teacher education programs and how to create multiple ways for Indigenous participation in teacher education and supervision. In addition, researchers may expand the sample size and examine more fully differences and efficacies between in-person supervision, supervision exclusively using technology, and blended models comparing supervision practices from other rural regions and countries. Such research efforts may identify different models and approaches about effective rural supervision practices.

\section{References}

Anderson, L. M., \& Stillman, J. A. (2012). Student teaching's contribution to preservice teacher development: A review of research focused on the preparation of teachers for urban and high-needs contexts. Review of Educational Research, 83(1), 3-69. http://dx.doi.org/10.3102/0034654312468619

Barley, Z. A. (2009). Preparing teachers for rural appointments: Lessons from the mid-continent. The Rural Educator, 30(3), 10-15.

Barnhardt, R. (2005). Indigenous knowledge systems and Alaska Native Ways of Knowing. Anthropology \& Education Quarterly, 36(1), 8-23. http://dx.doi.org/10.1525/aeq.2005.36.1.008

Bogdan, R., \& Biklen, S. K. (2007). Qualitative research for education: an introduction to theories and methods. Boston, Mass.: Pearson A \& B.

Boyd, D. J., Grossman, P. L., Lankford, H., Loeb, S., \& Wyckoff, J. (2009). Teacher preparation and student achievement. Educational Evaluation and Policy Analysis, 31(4), 416-440. http://dx.doi.org/10.3102/0162373709353129

Butler, B. M., \& Cuenca, A. (2012). Conceptualizing the roles of mentor teachers during student teaching. Action in Teacher Education, 34(4), 296-308. http://dx.doi.org/10.1080/01626620.2012.717012

Castagno, A., \& Brayboy, B. (2008). Culturally responsive schooling for indigenous youth: A review of the literature. Review of Educational Research, 78(4), 941-993. http://dx.doi.org/10.3102/0034654308323036

Cochran-Smith, M., McQuillan, P., Mitchell, K., Terrell, D. G., Barnatt, J., D’Souza, L., Jong, C., Shakman, K, Lam, K., \& Gleeson, A. M. (2012). A longitudinal study of teaching practice and early career decisions: A cautionary tale. American Educational Research Journal, 49(5), 844-880. http://dx.doi.org/10.3102/0002831211431006

Corbett, M. (2009). Rural schooling in mobile modernity: Returning to the places I've been. Journal of Research in Rural Education, 24(7), 1-13.

Creswell, J. W. (2007). Qualitative inquiry and research design: Choosing among five traditions (2nd Ed). Thousand Oaks, CA: Sage.

Cuenca, A., Schmeichel, M., Butler, B. M., Dinkelman, T., \& Nichols, J., R. (2011). Creating a "third space" in student teaching: Implications for the university supervisor's status as outsider. Teaching and Teacher Education, 27(7), 1068-1077. http://dx.doi.org/10.1016/j.tate.2011.05.003

Darling-Hammond, Linda. (2012). Powerful teacher education: Lessons from exemplary programs. San Francisco, CA: John Wiley \& Sons.

DeAngelis, K. J., Wall, A. F., \& Che, J. (2013). The impact of preservice preparation and early career support on novice teachers' career intentions and decisions. Journal of Teacher Education, 64(4), 338-335. http://dx.doi.org/10.1177/0022487113488945

Elliott, E. M., Isaacs, M. L., \& Chugani, C. D. (2010). Promoting self-efficacy in early career teachers: A principal's guide for differentiated mentoring and supervision. Florida Journal of Educational Administration \& Policy, 4(1), $131-146$.

Eppley, K. (2009). Rural schools and the highly qualified teacher provision of No Child Left Behind: A critical policy analysis. Journal of Research in Rural Education, 24(4), 24-4.

Faircloth, S. C. (2009). Re-visioning the future of education for Native youth in rural schools and communities. Journal of Research in Rural Education, 24(9), 1-4.

Fry, S. W., \& Anderson, H. (2011). Career changers as first-year teachers in rural schools. Journal of Research in Rural Education, 26(12), 1-15.

Glaser, B.G. \& Strauss, A.L. (1967). The discovery of grounded theory: Strategies for qualitative research. Chicago, IL: 
Aldine Pub. Co.

Goldhammer, R. (1969). Clinical supervision: Special methods for the supervision of teachers. New York: Holt, Rinehart and Winston.

Henry, G. T., Bastian, K. C., \& Fortner, C. K. (2011). Stayers and leavers: Early-career teacher effectiveness and attrition. Educational Researcher, 40(6), 271-280. http://dx.doi.org/10.3102/0013189X11419042

Hensley, P. H. (2003). The value of supervision. The Clinical Supervisor, 21(1), 97-110. http://dx.doi.org/10.1300/J001v21n01_07

Higher Education Opportunity Act of 2008, Pub. L. 110-310, §122, Stat. 3084 (2008).

Hill, A., \& Hirshberg, D. (2013). Alaska teacher turnover, supply and demand: 2013 Highlights (Report summary). Anchorage, AK: UAA Center for Alaska Education Policy Research.

Howley, C. B., \& Howley, A. (2010). Poverty and school achievement in rural communities: A social-class interpretation. In K.A. Schafft and A. Y. Jackson (Eds.) Rural education for the twenty-first century: Identity, place and community in a globalizing world (pp. 34-50). University Park, PN: Pennsylvania State University Press.

Ingersoll, R. M., \& Strong, M. (2011). The impact of induction and mentoring programs for beginning teachers: A critical review of the research. Review of Educational Research, 81(2), 201-233. http://dx.doi.org/10.3102/0034654311403323

Jung, L.A., Galyon-Keramidas, C., Collins, B., \& Ludlow, B.L. (2006). Distance education strategies to support practica in rural settings. Rural Special Education Quarterly, 25(2), 18-24.

Kisker, E. E., Lipka, J., Adams, B. L., Rickard, A., Andrew-Ihrke, D., Yanez, E. E., \& Millard, A. (2012). The potential of a culturally based supplemental mathematics curriculum to improve the mathematics performance of Alaska Native and other students. Journal for Research in Mathematics Education, 43(1), 75-113.

Kleinsasser, A. M. (2000). Researchers, reflexivity, and good data: Writing to unlearn. Theory Into Practice, 39(3), 155162. http://dx.doi.org/10.1207/s15430421tip39036

Kline, J., White, S., \& Lock, G. (2013). The rural practicum: Preparing a quality teacher workforce for rural and regional Australia. Journal of Research in Rural Education, 28(3), 1-13.

Kopcha, T. J., \& Alger, C. (2011). The impact of technology-enhanced student teacher supervision on student teacher knowledge, performance, and self-efficacy during the field experience. Journal of Educational Computing Research, 45(1), 49-73.

Krajewski, B., \& Jones, B. (1997). Student teaching supervision: A cross-cultural dialogue. Action in Teacher Education, 18(4), 77-82. http://dx.doi.org/10.1080/01626620.1997.10463366

Luke, A. (2012). Generalizing across borders policy and the limits of educational science. Educational Researcher, 40(8), 367-377. http://dx.doi.org/10.3102/0013189X11424314

McCracken, J. D., \& Miller, C. (1988). Rural teachers'perceptions of their schools and communities. Journal of Research in Rural Education, 5(2), 23-26.

Miles, M. B., \& Huberman, A. M. (1994). Qualitative data analysis: An expanded sourcebook (2nd ed.). Thousand Oaks, CA: Sage.

Moustakas, C. (1994). Phenomenological Research Methods. Thousand Oaks, CA: Sage.

Munsch, T. R., \& Boylan, C. R. (2008). Can a week make a difference? Changing perceptions about teaching and living in rural Alaska. The Rural Educator, 29, 14-23.

National Center of Education Statistics. (2010). Rural education in America. Retrieved from http://nces.ed.gov/surveys/ruraled/tables/a.1.a.-3_2010.asp

National Center of Education Statistics. (2011). National Indian education study 2011. [NCES 2012-466]. Retrieved from: http://nces.ed.gov/nationsreportcard/pdf/studies/2012466.pdf

Plonczak, I. (2010). Videoconferencing in math and science preservice elementary teachers' field placements. Journal of Science Teacher Education, 21(2), 241-254. http://dx.doi.org/10.1007/s10972-009-9166-3

Range, B. G., Young, S., \& Hvidston, D. (2012). Teacher perceptions about observation conferences: what do teachers think about their formative supervision in one US school district? School Leadership \& Management, 33(1), 61-77. http://dx.doi.org/10.1080/13632434.2012.724670

Reed, K. (2010). Multicultural education for rural schools: Creating relevancy in rural America. The Rural Educator, 
31(2), 15-20.

Reid, J. A., Green, B., Cooper, M., Hastings, W., Lock, G., \& White, S. (2010). Regenerating rural social space? Teacher education for rural-regional sustainability. Australian Journal of Education, 54(3), 262-276. http://dx.doi.org/10.1177/000494411005400304

Ronfeldt, M., Loeb, S., \& Wyckoff, J. (2012). How teacher turnover harms student achievement. American Educational Research Journal, 50(1), 4-36. http://dx.doi.org/10.3102/0002831212463813

Ryan, J., Jones, M., \& Walta, C. (2012). Creating a sustainable and supportive teaching practicum in rural and regional locations. Australian and International Journal of Rural Education, 22(1), 57-72.

Santoli, S. P., \& Martin, S. F. (2012). Learning together: Advancing the training of preservice teachers while training mentor teachers to lead. The New Educator, 8(4), 345-360. http://dx.doi.org/10.1080/1547688X.2012.726590

Slack, E., Bourne, L. S., \& Gertler, M. S. (2003). Small, rural, and remote communities: The anatomy of risk. A paper prepared for the role of government. Retrieved from http://www.law-lib.utoronto.ca/investing/reports/rp18.pdf.

Southgate, E., Reynolds, R., \& Howley, P. (2013). Professional experience as a wicked problem in initial teacher education. Teaching and Teacher Education, 31(0), 13-22. http://dx.doi.org/10.1016/j.tate.2012.11.005

Stake, R. (1995). The Art of Case Study Research. Thousand Oaks, CA: Sage Publications.

Stelmach, B. L. (2011). A synthesis of international rural education issues and responses. The Rural Educator, 32(2), $32-42$.

Strange, M. (2011). Finding fairness for rural students. Phi Delta Kappan, 92, 8-15.

Vallack, J. (2010). Subtextual phenomenology: A methodology for valid, first-person research. The Electronic Journal of Business Research methods, 8(2), 109-122.

Walker, D., \& Myrick, F. (2006). Grounded Theory: An Exploration of Process and Procedure. Qualitative Health Research, 16(4), 547-559. http://dx.doi.org/10.1177/1049732305285972

Wenger, K. J., Dinsmore, J., \& Villagómez, A. (2012). Teacher identity in a multicultural rural school: Lessons learned at Vista charter. Journal of Research in Rural Education, 27(5), 1-17.

White, S. \& Reid, J. (2008). Placing teachers? Sustaining rural schooling through place-consciousness in teacher education. Journal of Research in Rural Education, 23(7), 1-11.

Zeichner, K. (2012). The turn once again toward practice-based teacher education. Journal of Teacher Education, 63(5), 376-382. http://dx.doi.org/10.1177/0022487112445789

\section{(cc) $\mathrm{BY}$}

This work is licensed under a Creative Commons Attribution 3.0 License. 